\title{
Reflections on the implications of the empowered citizens at Alpha Media Holdings (AMH)
}

\author{
Innocent Fungai Chiyadzwa ${ }^{1}$ and Golden Maunganidze ${ }^{2}$ \\ 1 Great Zimbabwe University, Masvingo, Zimbabwe, \\ 2 Great Zimbabwe University, Masvingo, Zimbabwe.
}

\begin{abstract}
The print media plays a fivefold role of informing, educating, entertaining, providing a public sphere and acting as a surveillance mechanism to the governors and other key stakeholders. While this is undisputed and indeed noble, these functions comes with obligations and responsibilities to the communities they serve. As such it is imperative for the media to observe the societal norms and values as well as the ethics that guide them on a day to day basis. While it is clear and undoubted that professionals in the traditional media were trained to acquire the highest standards of journalism, the emergence of new media brought challenges whereby every person could report without hindrance and censorship. Every person thus became a 'journalist' and could therefore 'scoop' or break the news before the formal traditional mediums. This paper, thus strives to explore how Alpha Media Holdings (AMH) responded to the new challenge of bloggers and competition from citizen journalists. It also seeks to establish the push factors for the developing of a partnership between the newspaper stable and its readers. While the audience or readers were given space to air their sentiments through letters to the editor, opinion columns and through mobile short messages, the current trend where the audience are dubbed 'citizen journalists' by AMH and incentivised by remuneration makes it critical and worth academic attention as the question why arises. The paper used archival research and critical analysis to draw conclusions. It was concluded that the innovativeness at AMH is a survival strategy due to the industry-wide competition as well as to competition from real citizen journalists and it's also a cost cutting measure and a way of covering the widest geographical space in the country.
\end{abstract}

Key words: Citizen journalist, Alpha Media Holdings, Public sphere, Alternative media and Survival strategy

\section{Introduction}

The new media revolutionised the communication industry as it empowered previously disadvantaged audiences into becoming active producers of information. The new audience through blogs and social media also became educators, informers, watchdogs and indeed entertainers in their spheres of influence in life. The Habermasian public sphere was opened and participation on issues of national concern improved. Given this developing challenge the media reacted differently, this paper's thrust is on how and why Alpha Media Holdings sought to partner the 'citizen journalist' in a professional field reserved for journalists?

Alpha Media Holdings is a privately owned media group that runs two daily newspapers titled News Day and The SouthernEye, two weeklies The Independent and The Standard. The group is vital in the sector as it offers competition to the publicly owned Zimbabwe newspapers stable (Zimpapers) and other privately-owned stables in the country. This paper shall not concentrate on the ownership and structure of the newspaper industry in the country as this is well documented (Chari 2011 p.368), (Chiyadzwa and Maunganidze 2013, p.97), (Fredrikse 1982, p.40), (Mararike ,1997, p.51), (Mathema, 2001, p.10), (Maunganidze etal 2013, p.74), (Rusike, 1990, p.17), (Saunders, 1991, p.25), (Windrich, 1981,p.6). It shall however concentrate on Alpha Media Holdings as it is the case study in this paper. Ureke (2009:20) citing Munyuki sums the ownership of the stable as follows:

Originally the group, publishers of The Zimbabwe Independent and The Standard, was owned by Mike Curling and Clive Wilson, who later sold to a consortium of businessmen led by Trevor Ncube and Strive Masiyiwa, through his company Independent Media Group (IMG). The shareholding structure, according to Munyuki, is as follows:

\begin{tabular}{|c|c|}
\hline TS Holdings & (Ncube's) \\
\hline IMG & \\
\hline Nominees & \\
\hline
\end{tabular}

It should be noted that Newsday and Southern Eye are the last two acquisitions of the stable. The Alpha Media Holdings group perceives itself as:

"an independent media house free from political ties or outside influence. We have four newspapers: The Zimbabwe Independent, a business weekly published every Friday, The Standard, a weekly published every Sunday, and NewsDay, Southern Eye -our daily newspapers. Each has an online edition. In addition to that we 
have MyClassifieds, an online classifieds platform. The editorial board representing all three is totally committed to delivering accurate and impartial news designed to inform the public debate and enable Zimbabweans to make educated choices. Our pledge to those we serve is to seek the truth, deliver the facts and offer relevant context and analysis where appropriate. Our tone will be non-judgemental, objective and fair. In all cases we strive to include all relevant opinions and ensure that no significant strand of thought is neglected. We will strive to dig where others don't, give voice to the voiceless, shine a light in dark places, scrutinize the executive and hold the powerful to account - all on behalf of you, our audience, who we aim to serve with integrity offering journalism that is professional, credible, reliable, trustworthy, dependable and totally transparent. Our desire is create a conversation with Zimbabweans about the issues that matter in the country and enable maximum participation so that our newspapers and online offerings reflect as diverse a range of perspectives as possible. In so doing we hope to be part of the process of national healing, nation building, reconciliation and reconstruction. We aim to be a listening media organisation that deals with and reflects the issues that most concern those we serve. We want to help Zimbabweans to talk to each other without fear or favour and, through robust engagement, help ensure a tolerance society by encouraging the celebration of our diversity. Our newspapers and online sites are there to offer a canvas for Zimbabweans to showcase their best ideas to help transform the country into a knowledge-based society where citizens are free to express their creativity, ingenuity and entrepreneurship. We have set ourselves challenging objectives but we believe that only be striving to achieve the highest can we elevate ourselves above the elements which tend to hold our country back. However, if you see anything in print or online where you feel we may have failed to deliver on the pledges set out above, and where we may have failed on issues such as tone, impartiality, objectivity and fairness, please let us know by using the contact us form. We are here to listen and improve."

This study was necessitated by the need to explore the causes of the partnership between Alpha Media Holdings and its readers who they technically call citizen journalists. In their marketing concept of the idea AMH states "Do you have a picture, story, audio or video that you think will make an impact in your community. We want to give you a voice on our website." While this is noble as it is consistent with calls for a public sphere were more people participate openly the reasons for establishing such a platform as shall be argued in this paper goes beyond the need for community participation and development. The call also states that monthly a panel of selectors would reward prizes for the best story from a citizen journalist. Perhaps a lucid understanding of who is a citizen journalist would clear the air and guide the ensuing debate.

\section{Citizenship or citizen journalists?}

Citizenship according to the Collins Dictionary (174:191) denotes the condition or status of a citizen, with rights and duties. A citizen, the dictionary asserts is a native or naturalised member of a state, nation, or other political community. Imperative thus is the ability to participate in the affairs of the state nation or community that makes an individual eligible to be called a citizen. Borrowing from thus AMH seems to be taking members of the society as 'citizen journalists' as they contribute occurrences in their localities but are they?

The concept of citizen journalism (also known as "public", democratic, guerrilla or street journalism) is based upon public citizens "playing an active role in the process of collecting, reporting, analysing and disseminating news and information." Citizen journalism is a specific form of both citizen media and user generated content. New media technology, such as social networking and media sharing sites, in addition to the increasing prevalence of cellular phones, have made citizen journalism more accessible to people world-wide. Due to the availability of technology, citizens can often report breaking news more quickly than traditional media reporters (Freebase, Mashable, inc) thus citizen reporters are competing with formal mediums rather than aiding them, the situation thus called 'citizen journalism' by AMH is a misnaming and clearly diction used for specific reasons which is the subject of this paper.

Citizen journalism should not be confused with community journalism or civic journalism, both of which are practised by professional journalists. Collaborative journalism is also a separate concept and is the practise of professional and non-professional journalists working together. Collaborative journalism is more or less the concept being introduced by AMH as the untrained citizens make contributions that are then subjected to filtering and censorship by a trained journalist. Those that are inconsistent with the expectations of the newsman do not see any light at the end of the day. The presence of a gatekeeper at AMH to select the contributions implies thus that $\mathrm{AMH}$ and its contributors are partners thus are called collaborative reporters instead of citizen journalists.

Citizen journalism has an advantage of breaking news timeously without the conventions of traditional journalists who have to write and leave an editor to either approve or spike a story. In citizen journalism there is no gate-keeper and this poses challenges as in the process of presenting news they might violate the human rights of other people. The citizen journalists usually write to gratify themselves unlike trained journalists who 
are guided by legislative and ethical codes of conduct. It is the lack of societal obligation and lack of knowledge on media ethics which calls for possible regulatory measures against citizen reporters.

\section{Social media as alternative public spheres in Zimbabwe}

Habermas (1989) defines a public sphere as an ideal or the most appropriate platform which is conducive for intelligent deliberation on contemporary issues bedevilling any given society or group of individuals at a particular time. Thus the deliberations would reflect a proper functional democratic society which can freely come up with unanimous decisions in solving problems. Deliberations are therefore the most sought after possible way of solving a problem rather than coercion in democratic governance and decision making. The media have taken a leading role in providing the general public with a platform to debate issues that are affecting them. Often the general citizens who otherwise fail to have access to talk to government officials such as legislators and ministers can take advantage of newspapers to engage their leaders. For instance, in the Masvingo Star of 10 February 2014 there is an open letter to a Member of Parliament (MP) who seemed to be too shy to go back to his constituency, thus the media could be seen as that platform which encourages debate. Under normal circumstances, the named MP through the same newspaper would be expected to reply and give reasons for his perpetual absence.

However, for a long time, newspapers were known for employing a few journalists to report on issues taking place in a very huge space. Knowing journalists as ordinary human beings who are only qualified to do their trained job and nothing else beyond the skills acquired in colleges and universities, it would become a miracle for one person to be able to cover for example seven districts effectively. Nonetheless, AMH which owns newspapers such as News Day, The Standard, The SouthernEye and The Independent has only one correspondent who covers the whole of Masvingo province which comprises of two towns and seven growth points. Sadly, in a traditional set up, only the correspondent's voice or what that reporter believes to be newsworthy gets published at the expense of thousands of views of people living in the same area. Thus in light of the above argument and despite looking like an ideal Habemaserian public sphere, the traditional media seem to have its serious weaknesses. However, the coming in of the internet and indeed the advent of social media brought with it a new era regarding how public discussions and debates were to be handled. Suddenly the dialogue between the reader and the author became more vibrant with newspaper readers becoming more empowered and free to engage editors on issues they want to be reported. Both journalists and citizens started to compete for news for the same market. Again if the readers strongly believe that a published article lacked depth and is not balanced, they are free to confront the editor and give their own side of the story. In many cases of late, the editors or managers in various newsrooms under AMH and even other newsrooms in Zimbabwe can be forced to carry an article that can attack even their reporters due to the pressure which they get from the public. For example, when the media started to expose obscene salaries earned by top authorities and executive managers in government departments early 2014, one Cuthbert Dube the Chief Executive Officer of Premier Services Medical Aid Society (PSMAS) was among the named CEOs who were earning huge salaries. However, a prominent journalist who is a former Zimbabwe Union of Journalists president and now a commissioner with the Zimbabwe Media Commission (ZMC) Matthew Takaona wrote an opinion article in NewsDay of 29 January 2014 titled: Dont judge Dube harshly, however, due to hundreds of comments that came from readers, the newspaper was forced to carry another story on the following day titled: Shame on you journalist. This only acts to illustrate the power that can be possessed by a modern day reader. Knowing Takaona as a media commissioner and a senior newsman who has a distinguished history of excellence, one would think that readers would never have the temerity to challenge his opinion. Thus the organisation discovered that the only way to continue enjoying wide readership is by accepting their views on certain issues. This also helps advertisers to look for the media outlets in this organisation to market their services due to wide readership.

Earlier researches by scholars such as Max Horkheimer, Theodor Adorno, Herbert Marcuse and Walter Benjamin among others became popular for writing vitriolic criticism of not only advertising and the mass media but also the whole process of industrialisation and urbanisation as the twin engines that drive the capitalist system. In so doing, they came up with an idea of the culture industry where culture was being 'manufactured' for the consumption of the entire society. They were therefore more concerned with what the media do to the defenceless individuals and not the opposite, production of high and low culture and the enlightenment processes. Thus it proved that audiences are gullible individuals who cannot question the status quo. Audiences were therefore seen to be passive receivers who take media messages as gospel truth but the internet has nonetheless come to disturb the known tradition. Thus unlike in the past where the media had the sole mandate to set the agenda for the people, in the modern world of internet, anyone can influence the agenda. According to Mcombs and Shaw (1970), it's the media that tells the people what to think about but (agenda setting) with the advent of new technology, anyone who is able to read and write has the potential to influence the agenda. Faced with the reality that the internet is enough armoury that can assist their readers to challenge 
what comes out of newspapers, the AMH management therefore swiftly moved in to formalise social media as an alternative public sphere. The use of the internet has therefore been seen as empowering as the consumers become producers thereby becoming 'prosumers' of information. Their status as 'prosumers' gives them freedom, power and a voice to tell their story and generate content. Thus the internet offers an alternative digital public sphere where ordinary citizens meet and discuss issues could have never managed to get publicity.

\section{AMH promoting the voice of the voiceless}

Murdock (1992) and Curran (1996) argue that the public must have access to, and be able to use communication facilities in order to register criticism and propose alternative courses of action. Thus the coming of internet has provided a platform for the general public not only to have access to information but also a chance to challenge the status quo. Mitra (2001) argues that alternative online media give readers a voice to memorialise, a voice that authority cannot afford to ignore. Events worldwide have shown that new media are used by subaltern elements in society to challenge authority. It has almost become any media house's wish to be seen as the voice of the voiceless. A number of newspapers in Zimbabwe that include a leading private national daily The Daily News brags for being the voice of the voiceless. On the other hand, it had again proved that its very difficult to assess whether the media house would be true to itself by claiming to represent the underdog in the society. In fact members of the public continued to cry for publicity - a move that clearly demonstrated how the public sphere was domesticated by a few 'special publics' who would speak on behalf of the rest of the country. AMH introduced a programme which allows readers through a Whatsapp number to report or tell stories in their own language and angles.

In a bid to encourage their readers to participate on their AMH Voices section of their official website, the AMH management wrote this:

Do you have a picture, story, audio or video that you think will make an impact in your community? We want to give you a voice on our websites. The Whatsapp number is +263773245709. We would like to publish your photo, your audio and video. We already have overwhelming citizen journalism coming our way and we are loving it. Every month a team of selectors will award prizes for the best story, picture, audio and video. And we would like to give you an opportunity to be part of our team. Your stories and images will be on our websites under the section AMHVoices. Be the reporter and tell your on story. (News Day 23 January, 2014)

The above paragraph clearly highlights how the media organisation has officialised citizen journalism and subsequent new communication technology in story telling in Zimbabwe. Although they might have their own jobs, citizen journalists or readers who take their time to report what they want from their communities stand a chance to win some prizes. This is used as a motivating factor in order to have many people reporting thereby managing to come up with an active and effective dialogue with the people. With the coming in of this section in the newspaper, the ordinary people increasingly started to steal the professional newsman's job thereby leading the company's decision to downsize its staff.

\section{More news, cheap labour and need for retrenchment}

There is no doubt that Zimbabwe is still undergoing serious economic hardships with an ordinary citizen spending about US\$ 1 per day. According to the Consumer Council of Zimbabwe (CCZ), the country's poverty datum line is slightly above USD 500. In this situation, media organisations are not being spared as they are equally going under the same problems that are dogging the companies or factories in the economy. Reports in the public domain are that some media organisations are going for months without paying their employees. Zimbabwe Broadcasting Corporation (ZBC) in 2013 went for close to seven months without paying its employees. The situation in other newsrooms was equally bad with some newspapers such as The Mail closing shop within six months after hitting the streets.

Golding and Murdock, (2005) argue that a key feature of a critical political economy of communications is how private ownership and market systems of production and consumption can limit the democratic function of communications in a given social setting.

According to Schudson (2000) the market considerations create new forms of internal censorship. Thus the market can therefore become a key stakeholder in determining the product. As argued by Schudson (2000) media organisations survive on adverts hence they can indulge into some self-censorship ritual omitting content such as material critical of the advertisers' products. This is done to protect advertisers or to stop big business entities from withdrawing their adverts. The above practice can then result in self-censorship, with publications avoiding controversial coverage or content that advertisers may deem too critical. In this case, when adverts are plenty, the publication may not be worried about pushing volumes of newspaper sales. After all, the most important aspect of any business is its viability which often manifest itself in the profits generated per year or during a certain period of time. When newspaper companies therefore fail to reap anticipated profits, often they struggle to meet their obligatory roles such as paying salaries. Referring to the Zimbabwean situation, Chuma 
(2013) argued that there was no question about the poor salaries and bad working conditions faced by journalists working for almost all publications. Chuma (2013) further states that an average salary for a journalist was between US\$300 to US\$400 depending with the publication. He however, noted that editors were getting much higher salaries.

It is a fact that the general working conditions for journalists, from salaries to other incentives such as car, housing loans and the like, are not attractive at least in the eyes of the interviewees of the study (Chuma 2013:26)

Mchesney, therefore argues that advertising is at its peak when the economy is performing well. However, in Zimbabwe it becomes an open secret that the economy has been bleeding for almost two decades. The situation has also pushed business organisations to seek for other alternative survival strategies of which many of them saw withdraw of advertising in the media being one of their top options in their road to minimise costs and maximise profits. This is where newspapers woke out to find themselves filling up pages with inhouse adverts as the rate of advertising had reached its lowest mark in years. AMH as one of major players in the media industry in Zimbabwe also felt the heat as mainly evidenced by 'voluntary' retrenchment exercises by the country's newspaper giant.

Nonetheless, new problems often call for new solutions and in this case, at the AMH, the coming in of citizen participation would be seen as a blessing in disguise. The dwindling of workforce especially in the area of news gathering and reporting was supposed to see the company failing to meet its obligation of informing, educating and entertaining. The media world over are expected to be the watchdog. However, it can be very difficult to fulfil this fundamental obligation for any media house without adequate complimentary staff. The people dotted in various corners of the country who are either exited or saddened by events taking place in their areas continue had almost become a threat to the mainstream media as they created their blogs and Facebook pages where they would communicate and share stories among themselves and their readers. Chuma (2013) argued that the internet brought its fare share of problems to the mainstream media.

Media organisations themselves are operating in a tough economic environment and are also having to adjust their operations profoundly to survive in the era of the internet. (Chuma 2013:26)

However, innovation and creativity at the AMH saw the newspaper giant becoming the first stable in the country to formalise the voices of an ordinary reader. There was a formal recognition of the power of the reader in either objecting or agreeing with certain stand points in issues reported by the press. This is when AMH invited its readers to join voices and speak to each other at a platform where they could be easily heard and recognised. When their voices were put together, they changed status from a mere reader or participant to become AMH voices. This meant that their voices would pass through a gate where hostile and unpalatable contributions or views would have to be tried and denied publication upon deemed unfit for consumption. In the same way that a story could be edited or spiked out by the editor in a newsroom is also the manner in which the would-be AMH voices can be edited and 'rejected' or 'accepted'. Readers therefore thrive to provide the best picture or story in order to pass the test but by so doing, they become very critical in replacing the vacuum left by retrenched workforce.

\section{Who is a journalist then?}

The question of who journalists are has never been definitively answered, in part because journalists themselves often don't want to be licensed, certified or classified by any official authority or by anyone outside journalism, and in part because there is no specific body of knowledge that journalists must master to practice their craft (Weaver: 1992: 47).

Tunstall (1973) described journalism as a vague profession which cannot be easily defined. Unlike other well defined professions such as law and medicine which have proper known parameters within their operations as well as certified codes of ethics 'journalism' can therefore be seen as a mere label which people can engaged in a very diverse range of activities.

This diversity, as we have seen, has increased considerably in the past thirty years and 'only occupations which are fairly determinate have any chance of becoming professions' probably relegates journalism's position even further nowadays from professional status. (Tunstall, 1973: 98)

Thus in view of the above assessment, academics since history immemorial doubted that journalism would ever become any other profession like medicine, law and engineering among others. It could therefore become crystal clear that journalism could risk to never acquire professional attributes. To this end, it could thus be concluded that a more realistic objective, if the occupation or 'craft' wished to pursue it, would be to make journalism into a semi profession.

It can also be argued that the question about the qualification needed to qualify as a journalist has been asked countless times but unfortunately the debate remains open as researchers continue to solicit for an ideal answer. According to Adam (2001) the education of professional journalists, at least for the European and American context, has failed to produce clear professional and pedagogical criteria which would allow 
journalistic education to achieve a degree of legitimacy and prestige similar to that enjoyed by medical and law studies.

However, by whatever name you give them and by any qualification they require, those men and women who write stories for newspapers and media organisations are very critical for the survival of those institutions. Thus AMH's survival even in the absence of trained people from different schools of journalism can therefore be guaranteed. Through legalising citizen participation or by giving audiences a chance to speak among themselves in itself has become a job threat to those who go to schools of journalism and spent years learning about the $5 \mathrm{ws}$ and $\mathrm{H}$ of how to write news. No matter how knowledgeable they are, the fact that their mobile phones can assist them to take picture, that enough can cost someone's job because what one would want a salary to do, another one can do it for pleasure. Worldwide newsrooms are downsizing because of one reason or another but for AMH in Zimbabwe, it seems the internet has stolen the newsman's job.

According to the story titled: 51 workers leave AMH, The Herald of February 4, 2014, AMH embarked on a retrenchment exercise and about 51 workers including journalists had left their job in phases one and two of the same exercise. The company's publisher Rita Chinyoka is quoted saying AMH was welcoming more resignation letters from employees. Although there could be other hundreds and thousands of reasons for taking that action, it is vivid that the citizens who used to be passive readers are slowly getting on the steering wheel and with few instructions from the instructors, they are threatening to take over.

\section{1) Competition from bloggers and social media}

\section{Factors influencing AMH to formalise 'citizen journalist'}

In Zimbabwe, the internet has been unprecedentedly a platform for all as witnessed by the mushrooming of alternative news dissemination platforms. There is also growing reliance on posts by bloggers and most people now rely on mobile news for updates and also for updating colleagues and friends on occurrences. It is in this vain that $\mathrm{AMH}$ became innovative so as to tame competition. The remuneration they offer to outstanding contributors per month reflects that the group intends to minimise competition from bloggers and citizen journalists by making them a part of the stable.

\section{2) Industry-wide competition}

The newspaper industry in Zimbabwe has been growing and according to Media Commissioner Mathew Takaona during a guest lecture at Great Zimbabwe University (May 2013), about 74 new players were licensed by the Zimbabwe Media Commission in 2013 alone. Given this trend AMH want to harness citizens scattered all over the country to scoop and break news before any other stable does so. The competition posed by the public media and other privately owned newspaper-stables in the country has led AMH to domesticate citizen reporters. By using citizens the group covers the widest geographical areas thus becomes relevant to many unlike relying on news from the main cities only as was the case prior to the rise of the alternative media.

\section{3) Cost cutting measures}

AMH by relying on citizen reporters is cutting costs related to employing professionals such as journalists and photographers all over the country. The recent call for retrenchments and resignations at AMH supports this assertion as there is no need to hire more staff when the job can be done by untrained citizens who have no demands for equipment of the trade and who are not on the payroll. The initiative though empowering the audience is detrimental to employment-hopeful trainees in journalism and media studies.

\section{4) Survival strategy}

The lack of viability in Zimbabwe caused early investors into newspaper business such as The Daily Gazette to fold due to high operational costs. Bearing this in mind AMH thus is innovative and this empowering of citizens to report can go a long way in ensuring that the stable remains in business while minimising news gathering costs. This is reiterated by Chiyadzwa and Maunganidze (2013) who argued that newspapers in Zimbabwe were closing due to harsh economic situation faced by the country as a result every stable worth its salt had to employ various survival strategies inorder to keep their head above water.

\section{5) Need for more readers and audiences on their website}

The initiative where readers feel as part of the group increases the company's ratings as the gratification seeking so called reporters would market the idea to family and friends as they desire to be heard, seen and to brag about their contributions.

\section{6) Scooping and wider-geographical coverage at low cost}

The contributions from people who are in different places of the country makes scooping easy for Alpha Media Holdings as the contributors becomes news sources who can be tasked to verify occurrences and to report 
accordingly. The fact that citizen reporters are driven more by the desire to see coverage of their local events as opposed to remuneration also explains the introduction of the concept.

\section{Conclusion}

In Zimbabwe, the law requires practising journalists to be registered by the Zimbabwe Media Commission but they are no stipulations for citizen journalists. It is against this background that AMH has been maximising on citizen contributions to gather news without any legal bottlenecks. The fact that the news reports from citizens is subjected to thorough gate-keeping and editing requires that the contributors should be formalised so that trained personnel are not disadvantaged. Currently there are ten journalism training institutions in the country and the expectation for all trainees is that they will be accommodated in the sector as such media houses are encouraged to hire trained personnel to do the gathering and dissemination of news. The reliance on contributions by citizens compromises the profession as they do not abide and are not bound by the ethical considerations and standards set by the Voluntary Media Council of Zimbabwe which Alpha Media Holdings ascribe to. Indeed just like in professionals such as law and medicine the media sector should be left to practitioners on the payroll to do their duties.

\section{References}

[1] Adam, S.G. (2001) 'The Education of Journalists', Journalism, 2(3): 315-339

[2] Chuma W, (2013), The State of Media Ethics in Zimbabwe, VMCZ, Harare

[3] Frederikse, J. (1982). None But Ourselves: Masses vs Media in The Making of Zimbabwe, Harare: Zimbabwe Publishing House.

[4] Golding, P. and Murdock, G. (1991) in Curran, J. and Gurevitch, M. Culture Communications and Political Economy: London, Sage

[5] Habermas, J. 1989. The Structural Transformation of the Public Sphere. Cambridge: Polity Press.

[6] Rusike, E.T.M. (1990). The Politics of the Mass Media: A Personal Experience, Harare: Roblaw Publishers limited.

[7] Mararike, C.G. (1997). A Historical overview of the media and political change in Rhodesia, Gweru: Mambo Press.

[8] Mathema, N.C.G. (2000). Newspaper in Zimbabwe, Lusaka: Multimedia Publications.

[9] McChesney, R. (2009) "Political Problem, Political Solutions", in Duffy, B.E. and Turow, J. (eds) Key Readings in Media Today: Mass Communication in Contexts. New York: Routledge.

[10] McCombs, M.E. and Shaw,D.L. (1972) The Agenda Setting Function of the Press. Public

[11] Opinion Quarterly 36: 176-87.

[12] Saunders, R. (1999) Dancing out of Tune: A History of The Media in Zimbabwe, Harare: Edwina Spicer Productions, Brylee Printers.

[13] Schudson, M. (2001) "The objectivity norm in American journalism," Journalism 2, 2:149-170.

[14] Ureke,O. (2009) State interference in the media. An investigation of factors leading to the closure of the Zimbabwe Mirror Newspapers Group. Unpublished MSC thesis, Midlands State University.

[15] Weaver, D.H. and Wilhoit, G.C. (1996) The American Journalist in the 1990s. New Jersey: Lawrence Erlbaum Associates.

[16] Windrich, E. (1981). The Mass Media in the Struggle for Zimbabwe: Censorship and Propaganda under Rhodesian Front Rule, Gweru: Mambo Press.

\section{JOURNAL ARTICLES}

Chari, T. 2011. Future Prospects of the print newspaper in Zimbabwe. Intellect 367-388.

Chiyadzwa I.F and Maunganidze G. 2013. Survival strategies of community newspapers during the economic crisis in Zimbabwe: A case study of The Mirror and Masvingo Star (1999 to 2010).IJSSI. May 2013.95-100. Maunganidze G., Chiyadzwa I.F and Tobias D. 2013. Reflections on emerging horse and rider relationship: Media relations between Zimbabwe and China.IOSR. Nov-Dec 2013. 72-78.

Tunstall, J. (1973) 'Journalism as an Occupation', The Medico-Legal Journal, Part Three, $87-101$.

Websites

www.freebase.. rg

www.newsday.co.zW

http://bulawayo24.com/index-id-news-sc-national-byo-42320-article-

Publishers+of+NewsDay+embarks+on+phase+three+retrenchment+programme.html

https://www.newsday.co.zw/2014/01/29/dont-judge-cuthbert-dube-harshly/

https://www.newsday.co.zw/2014/01/30/shame-journalist/

Masvingo Star newspaper of 10-16 February 2014 